Carlos Eduardo Dias Comas, arquiteto Carlos Eduardo Dias Comas

(FAU-UFRGS), mestre em arquitetura e em desenho urbano (Universidade da Pensilvânia).

Além de desenvolver prática privada, é professor adjunto da UFRGS, onde atualmente acumula o cargo de chefe do departamento de Arquitetura com o de coordenador de ensino do curso de especialização em arquitetura habitacional mantido pelo Programa de Pesquisa e Pós-Graduação em Arquitetura - PROPAR.

\title{
O espaço da arbitrariedade
}

O espaço da arbitrariedade: considerações sobre o conjunto habitacional BNH e o projeto da cidade brasileira

Desde a criação do BNH, em 1964, os produtos mais conspícuos de sua atividade têm sido os conjuntos habitacionais para população de baixa renda, implantados em larga escala na rede urbana brasileira. A expressão conjunto habitacional BNH evoca hoje bem mais que o seu significado estrito de conjunto de habitações. Primeiro, empreendimentos imobiliários de porte considerável - conjuntos de quinhentas unidades habitacionais para 2.000 a 2.500 pessoas são mais a regra que a exceção. ${ }^{1}$ Segundo, localização em periferia ou antigo vazio urbano de dimensões avantajadas. Terceiro, duas fórmulas de projeto usádos isoladamente ou em justaposição. Uma é o conjunto de blocos repetitivos de apartamentos, usualmente sem elevador, não ultrapassando quatro pavimentos. Complementados por equipamentos recreativos e/ou assistenciais constituindo construções térreas isoladas, os blocos identificam-se numericamente; suas portas de ingresso não guardam relação consistente com as ruas internas ou periféricas ao conjunto. Os espaços abertos entre edificações não ocupados por ruas ou estacionamentos descobertos são sempre coletivos e nunca compartimentados, permitindo livre acesso a todos os moradores e à vizinhança. Na maioria das vezes, não recebem tratamento algum que os diferencie em lugares distintos, embora ocasionalmente registre-se a presença de play-ground ou quadra esportiva em seu interior. Os apartamentos são pequenos; áreas de serviço minúsculas induzem os moradores a instalar estendedores de roupa retráteis, pro- jetando-se para fora das fachadas rebocadas. A construção é de alvenaria, geralmente de nível baixo. A outra fórmula não se distingue de uma urbanização modesta de casas unifamiliares isoladas, a não ser pela repetitividade dos telhados de fibrocimento sobre lotes entre 160 a $240 \mathrm{~m}^{2}$, que conformam quarteirões estreitos e compridos.

Em qualquer uma dessas fórmulas, podemos pensar no conjunto habitacional BNH como um tipo arquitetônico. Um tipo arquitetônico constitui esquema mental complexo, culturalmente cofidificado por intermédio de uma prática social, que associa determinadas configurações físicas a um problema usual de projeto do ambiente construído. Podese vê-lo como um veículo de informações condensadas, onde a definição genérica da natureza das finalidades, disponibilidades e limitações que caracterizam o problema é dada simultaneamente com a definição genérica das características geométricas, técnico-construtivas e figurativas de sua solução arquitetônica. Por um lado, o tipo é instrumento classificatório a posteriori, que ressalta as características comuns de obras arquitetônicas já executadas. De outro, o tipo funciona como um instrumento apriorístico de projeto, princípio normativo comum de realizações fisicamente similares, ainda que não necessariamente idênticas. O tipo se viabiliza como tal pelas evidentes vantagens de tempo, esforço e dinheiro que decorrem do emprego de soluções semelhantes.

Infelizmente, porém, um tipo pode ser consagrado prematuramente por meio de mecanismos institucionais e ideológicos, sem escrutínio crítico suficiente da adequação entre problema e solução promovida. Tal parece ser o caso do conjunto habitacional BNH. Três aspectos corriqueiros e insatisfatórios do conjunto de apartamentos BNH nos inte- 
ressam aqui: as possibilidades limitadas ou nulas de uso efetivo de espaços abertos percebidos como 'terras de ninguém' residuais entre edificações; a ausência de privança dos apartamentos térreos que defrontam esses espaços; as dificuldades de orientação, parciais ou globais, que podem se creditar, em primeira instância, à repetitividade de blocos iguais em grande escala e à ausência de diferenciação clara e consistente de suas entradas, legível desde ruas e caminhos do conjunto. A ocorrência sistemática dessas deficiências de habitabilidade ou deseconomias pertuba. O silêncio da intelligentsia arquitetônica brasileira a seu respeito intriga, tanto mais que esta, inúmeras vezes, chamou a atenção para as deseconomias evidentes do conjunto de casas BNH, absolutamente perdulário se considerarmos a infra-estrutura viária que exige.

Ocorrência e silêncio só são compreensíveis se lembrarmos que, para a intelligentsia arquitetônica brasileira, o conjunto de apartamentos BNH não passa da versão abastardada, por injunções econômicas especulativas, do tipo ideal de moradia que sua formação preconizou e que a superquadra residencial de Brasília materializa. Nos seus $400 \times 400 \mathrm{~m}$, blocos repetitivos de apartamentos com elevador se destacam do solo por meio de pilotis, procurando não ser mais que instrusões discretas num jardim coletivo luxuriante. Prédios baixos isolados para recreação e serviços adicionam-se aos blocos de apartamentos, quase desaparecendo em meio à exuberância vegetal. Os automóveis abrigam-se em subsolo, após percorrer ruas internas sinuosas sem saída. Comércio para abastecimento diário ocupa cabeceira de superquadra, que não se pretende autosuficiente porque é componente básico de uma cidade ideal moderna, por sua vez ilustrada quase literalmente pelo plano piloto de Brasília. ${ }^{2}$

Formulada e defendida pela vanguarda arquitetônica européia em meados da década de 1930, é a cidade planejada de solo totalmente público. Zoneada monofuncionalmente, suas superquadras constituem unidades mínimas de divisão e intervenção territorial, onde torres cristalinas ou barras em pilotis para habitação, comércio e serviços sobressaem de um parque natural. O parque não está na cidade; a cidade está no parque. A continuidade e a homogeneidade do verde só é interrompida por edificações baixas para o 'cultivo do corpo e do espírito', campos de jogo e uma rede viária hierarquizada, feita sob medida para o automóvel privado. 0 formato da 'cidade ideal moderna' pode ser descrito como a acumulação de objetos construídos em um contínuo tratado como parque basicamente indiferenciado, cortado por autopistas e caminhos. Em contraposição, o formato da cidade tradicional pode ser descrito como a acumulação de espaços vazios - ruas e praças configuradas por fachadas con- tínuas alinhadas - dentro de uma massa construída predominantemente indiferenciada, perfurada por pátios e quintais privados. Desde o ponto de vista perceptivo, no formato tradicional, a figura é o espaço, o fundo é construção. No formato modernista, a figura é o edifício, o fundo é paisagem (Rowe; 1978).

A 'cidade ideal moderna' é a etapa final de um processo de duas décadas. Nela, a vanguarda arquitetônica européia do entre-guerras afirma a necessidade imperiosa de rejeitar as especificações quantitativas e qualitativas de um urbanismo de rua, praça, quadra, lote, fachada, alinhamento, pátio e quintal. Proclama e celebra incisivamente sua substituição por uma paisagem de autopistas, caminhos, parques e edificações isoladas em superquadras, partindo-se da percepção de conflitos e lacunas na cidade burguesa desenvolvida de então.

Suas ruas congestionadas não conseguiam atender às demandas de um tráfego motorizado de intensidade crescente, gerador de ruídos, gases nocivos e acidentes. Suas quadras estavam ocupadas por edificações cujos compartimentos eram iluminados e ventilados por poços e pátios de dimensões incompatíveis com padrões higiênicos mínimos. Seus bairros populares centrais, superpovoados, careciam de espaço aberto e equipamento para esporte e recreação. Quando indústrias poluentes vizinhavam com a moradia, colocava-se em risco a saúde das massas urbanas. Se estas alojavam-se em loteamentos suburbanos, as viagens entre moradia e trabalho convertiam-se em sacrifícios diários. O crescimento físico incontrolado da cidade burguesa servia primariamente aos interesses imediatistas da especulação imobiliária, em detrimento de sua economia e funcionalidade globais. A situação requeria cirurgia radical, que utilizasse plenamente o potencial de um progresso tecnológico e científico sem precedentes.

A prescrição de superquadras e trama viável hierarquizada permitiria maior economia e eficiência no tráfego. Acompanhada de organização vertical do movimento veicular, reduziria o número de cruzamentos em nível, possibilitando maiores velocidades e minimizando conflitos entre diferentes tipos de tráfego e entre movimento veicular e movimento pedestre. O interior de superquadra tornar-se-ia recinto privilegiado de pedestres, que não tardariam mais de dez minutos em percorrer o trajeto entre seus pontos mais distantes. A ausência de parcelamento interno da superquadra endossaria tendências percebidas de concentração de capital no setor imobiliário; incentivaria a formação de grandes empresas construtoras, capazes de reduzir custos de construção graças à aplicação intensiva de métodos e técnicas industriais. Os edifícios altos viabilizados pelo elevador e pela construção em concreto ou aço po- 
"deriam distribuir-se livremente sobre as superquadras, obtendo-se, ao mesmo tempo, densidades elevadas e altas percentagens de espaço aberto. As condições de insolação, iluminação e ventilação naturais resultariam excelentes.

Sobraria espaço para esporte e recreação junto à moradia. A satisfação das necessidades ambientais do homem-tipo anônimo da sociedade de massas não reclamaria mais que um reduzido número de tipos de acomodação residencial, comercial e industrial, perfeitamente adequáveis à lógica interna de uma produção em grandes séries pré-fabricadas. 0 planejamento racional centralizado da produção e do território permitiria estender a todas as classes os privilégios ambientais tradicionalmente reservados às minorias dominantes. A propriedade pública do solo impediria a especulação imobiliária. Levantada sobre terreno virgem ou arrasado, a 'cidade ideal moderna' evitaria qualquer compromisso com a complexidade social, econômica e física do contexto canceroso que substituiria.

O conjunto de apartamentos BNH é comparável à superquadra residencial modernista no porte, na divisão programática entre habitaç̃o coletiva e seus complementos, no emprego de edificações isoladas dissociadas da rua e dispostas sobre espaco aberto contínuo, coletivo, indiferenciado. Faltam, porém, o elevador, os pilotis que eliminariam a ausência de privança registrada nos apartamentos térreos, os estacionamentos em subsolo e o tratamento do espaço aberto como jardim inglês tropicalizado à la Burle Marx - que a superquadra de Brasília ostenta. É claro que a ausência desses elementos é creditável a limitações de orçamento. As superquadras de Brasília abrigam famílias de classe média alta em apartamentos cuja área é, pelo menos, o dobro dos $50 \mathrm{~m}^{2}$ do apartamento da família entre três e doze salários mínimos de renda que mora no conjunto $\mathrm{BNH}$. Contudo, seriam o elevador, os estacionamentos em subsolo, os pilotis e o jardim indispensáveis ou prioritários para qualificar a moradia? O senso comum obriga a responder com um não rotundo. Certamente, o elevador e o estacionamentto coberto em subsolo aumentam o conforto proporcionado por bloco de apartamentos - a um preco substancial. Escadas até quatro pavimentos e estacionamentos ao ar livre são substitutos perfeitamente aceitáveis. Além disso, uma extensa literatura sobre edifícios altos de apartamentos reduzidos sugere que eles não são também acomodação satisfatória para famílias com crianças pequenas. A intensidade de uso dos pilotis e do jardim à la Burle Marx de Brasília dificilmente recomenda o seu emprego normativo: são itens de luxo, não gênero de primeira necessidade. A economia no projeto da habitação popular é requerimento fundamental. Não se trata de mera questão de especulação. Mesmo admitido que os meca- nismos sócio-econômicos que condicionam a sua produção devam ser discutidos e modificados, o vulto do déficit a ser superado torna plausível pensar que, a curto e médio prazo, a escassez de recursos continuará condicionando-lhes projeto e realização. Enfim, apartamentos térreos não são inabitáveis por princípio; se sua situação acarreta problemas de privança a resolver, também oferece oportunidade de acesso e/ou contato com o espaço aberto adjacente.

É claro que, para solucionar esses problemas ou aproveitar essas oportunidades, o espaço aberto adjacente a apartamento térreo teria de ser protegido ou privatizado. Proteção ou privatização exigiriam a introdução de alguma espécie de barreira no espaço aberto; se isso ocərresse, porém, sua continuidade sofreria interrupção, ou mesmo ele cessaria de ser coletivo em sua totalidade. Desobedecerse-iam as prescrições normativas modernistas. Entretanto, por que todo espaco residencial urbano deveria necessariamente ser coletivo e continuo? Ainda que se admita a desejabilidade da propriedade pública do solo urbano, direito de propriedade não se confunde com direito de uso. Não decorre dai que seja sempre indesejável a inexistência de controles de acessibilidade ao espaço aberto residencial e que, conseqüentemente, seja sempre indesejável sua compartimentação. Cercas altas fazem os bons vizinhos, afirma um velho ditado, reconhecendo que liberdade de conduta não equivale a espaço livre de barreiras físicas. Paradoxalmente, sua ausência pode mesmo constituir fator de repressão de compor tamento. A 'cidade ideal moderna' reduz os múltiplos niveis e escalas de interação comunitária urba na - que demandam expressão e identificação ter ritorial - à polaridade espaço aberto coletivo do par que/espaço coberto privado do bloco e unidade ha bitacional. É proposição simplista a que ignora ser a caracterização de território uma necessidade humana básica (Sommer; 1969).

Além disso, a prescrição modernista de tratar qualquer espaço aberto urbano como parque também suscita reservas funcionais e econômicas. $\mathrm{Pa}$ ra animar as quantidades ilimitadas de parque que a 'cidade ideal moderna' propõe, a população urbana teria de dedicar-se à recreação ao ar livre em regime de tempo integral (Jacobs; 1961), abandonando outros interesses e ocupações. Parques são necessários na cidade, mas o repertório de tipos desejáveis de espaços abertos urbanos não se reduz a ele; parques também não são habitualmente dádivas da natureza. Como qualquer outro espaço destinado ao uso humano, sua implantação e conservação custam dinheiro; sua raridade relativa estimula a freqüência e faz mais sentido do ponto de vista da relação entre custo e uso efetivo. 
Assim, não causa surpresa que o parque da 'cidade ideal moderna' degenere e forme um descampado de grama rala no conjunto habitacional modesto. Associado a blocos repetitivos de desenho monótono, não estranha que seja percebido como 'terra de ninguém' pública, oferecendo oportunidades mínimas de identificação territorial. Ao desolamento patético soma-se uma vulnerabilidade flagrante; o efeito resultante é inibidor, pouco convidativo a uma apropriação de uso. É violento o contraste visual com superquadras mais atingas da Asa Sul em Brasília, ou com empreendimentos imobiliários recentes em São Paulo e outras capitais brasileiras, projetados para classe média alta ou classe alta, de acordo com princípios modernistas. Em tais exemplos, um orcamento generoso permite tanto tratamento paisagístico elaborado dos espaços abertos coletivos como sua manutenção impecável. Não importa que seu uso efetivo seja limitado, que sua função primária seja ornamental. Afinal, trata-se de um símbolo exclusivo de status, garantido quer pelas cercas, guaritas e guardas fortemente enfatizados na promoção desses empreendimentos, quer pela barreira de verde e distância que segrega as cidades satélites do Plano Piloto de Brasília... Para completar, não deixa de ser curioso que o morador do conjunto habitacional BNH deva pagar - do seu 'bolso farto' - não só a implantação mas também a manutenção do espaço recreativo público da vizinhança. Em Brasília, ao menos, é o poder público quem conserva o verde de superquadra.

Ironias à parte, a ausência de compartimentação territorial na superquadra não pode ser justificada como imperativo funcional, nem sequer como imperativo técnico-econômico. Ė correto afirmar que a eficiência e economia do movimento da cidade aumentam com a hierarquização de ruas por capacidade e tipo de tráfego e é certamente valiosa correlação entre velocidade da marcha pedestre e uma área de $400 \times 400 \mathrm{~m}$. É importante dar-se conta de que o planejamento de áreas dessas dimensões oferece oportunidade na distribuição de volumes construídos, espaços abertos e canais de movimento mais amplos que as resultantes de um parcelamento da mesma partindo-se de pequenos lotes convencionais. Entretanto, daí não se segue que a unidade mínima de divisão territorial urbana deva ser a superquadra. A recíproca faz mais sentido: a superquadra de $400 \times 400 \mathrm{~m}$ é a unidade máxima de divisão territorial urbana para fins residenciais que não é cortada por vias veiculares. No projeto de áreas habitacionais de densidade elevada (o que não é o caso das superquadras residenciais de Brasília), exigências de acessibilidade veicular favorecem a sua desagregação em unidades menores. Por outro lado, mesmo que a lógica produtiva favoreça a concentração do capital no setor de construção, não decor- re daí que o planejamento unitário de gleba do tamanho de superquadra não possa nem deva contemplar sua desagregação em módulos de intervenção menores, parcial ou totalmente limitados por vias veiculares, sem prejuízo de uma correta hierarquização viária. Não precisaríamos de muita imaginação para batizá-los: 'quadra' seria designação bem apropriada. Note-se que a desagregação seria mais compatível com uma implantação em etapas territorialmente definidas, prestando-se melhor a eventuais modificações do programa de construção no tempo. O fato relevante a observar é que a quadra não deve ser o resultado da adição de lotes de qualquer tamanho, mas da consideração simultânea de exigências externas de acessibilidade e economia viárias e de exigências internas de organização físico-funcional de edificações e espaços abertos, apoiada em constatações tão simples como a de que, para uma mesma área, o quarteirão quadrado tem o perímetro menor que o de quarteirão retangular, resultando em menor requerimento de espaço de rua. Em qualquer caso, existe correlação entre infra-estrutura viária, configuração e dimensões de quadra e parcela e tipos de edificação e espaço aberto no interior das mesmas, que deve ser vista de modo abrangente.

Do ponto de vista do uso econômico do solo urbano, essa correlação não apóia taxativamente a prescrição modernista de edifícios altos sobre a superquadra, como o indicam estudos combinados de uso do solo e edificação realizados na Universidade de Cambridge e publicados por Leslie Martin e Lionel March (1972) sob o título Urban space and structures. Considerando um universo de formas retangulares (que se recomendam por fácil demarcação e registro legal, elevado grau de potencial associativo, simplicidade construtiva, resultados satisfatórios na organização da trama viária urbana etc.), a multiplicidade de volumes edificáveis pode ser reduzida a três tipos plani-altimétricos básicos. Estes são o pavilhão ou torre, a barra e a cruz. O pavilhão ou torre é volume finito; a barra é edificação potencialmente infinita ao longo de um eixo; a cruz é edificação potencialmente infinita ao longo de dois eixos perpendiculares. Destes tipos se podem derivar matrizes formais retangulares; as barras paralelas geram uma matriz de ruas, as cruzes geram uma matriz de pátios. Podemos considerar essas matrizes como pontos definidos em um processo contínuo de transformações morfológicas, no qual pavilhões ou torres isoladas alongam-se até formarem fitas contínuas paralelas, que, por sua vez, se modificam até formarem uma malha quadrada prismática. Foram elaborados e analisados modelos matemáticos teóricos, descrevendo a variação do índice de aproveitamento - isto é, a área construída por área de terreno - de cada uma dessas matrizes para um número va- 
riável de andares, em um mesmo terreno. A análise desses modelos mostra que o índice de aproveitamento do conjunto de pavilhões ou torres decresce, partindo-se de um certo número de andares a cidade das torres descontínuas é intrinsecamente ineficiente em termos de aproveitamento do solo. Examinando o comportamento em uma mesma área de terreno das três matrizes e supondo-se constantes a profundidade edificada, o afastamento entre lados opostos da edificação, levando-se em conta a mesma altura total e a mesma altura entre pisos, verifica-se que, quando o índice de aproveitamento do conjunto de pavilhões ou torres atinge o seu valor máximo, o índice de aproveitamento de barras paralelas é duas vezes maior e o índice de aproveitamento de uma matriz cruciforme é três vezes superior. Em outras palavras, para um mesmo índice de aproveitamento, a altura de barras paralelas é duas vezes menor que a altura de um conjunto de pavilhões ou torres, a altura de uma matriz cruciforme é três vezes menor; uma matriz anelar quadrada, comparável à uma edificação com pátio central, comporta-se de maneira análoga à matriz de barras paralelas. Ainda que os estudos acima resumidos partam de hipóteses simplificadoras, é insustentável qualquer defesa econômica de torres isoladas sobre o parque.

A promoção de edifícios altos pela vanguarda modernista européia apóia-se num ensaio famoso de Walter Gropius. ${ }^{3}$ Este mostra que, mantido constante o ângulo de obstrução solar entre barras paralelas iguais, em um sítio retangular plano de área dada, a área edificável aumenta com o número de andares; dada uma área total de construção a distribuir homogeneamente por barras paralelas iguais de afastamento controlado por ângulo de obstrução solar constante, a área do terreno necessário diminui com o número de andares; dada uma área total de construção a distribuir homogeneamente por barras paralelas iguais em um sítio retangular plano de área dada, o ângulo de obstrução solar diminui com o número de andares. Gropius defendia edifícios de dez a doze andares.

Contudo, March (1972) aponta que uma apreciação cuidadosa do modelo matemático mostra que, após certo número de andares, os ganhos são despreziveis, porque sua variação é hiperbólica. Uma observação mais calibrada favoreceria soluções mais baixas, quer em forma de barras paralelas, quer em forma de pátio central.

Convém reparar que, de modo algum, as conclusões anteriores são extrapoláveis para torres isoladas ou referendam a disposição 'livre' de blocos em superquadra. Faz-se mister respeitar uma geometria ortogonal de base. Esta geometria implica, no mínimo, alinhamento parcial de barras paralelas contí- nuas em face das ruas limítrofes de superquadra. Do ponto de vista de uma geometria econômica do espaço urbano, é discutível a regra modernista que prescreve transformar necessariamente a rua de feição tradicional em estrada ou caminho dando acesso a edificações descontínuas e desalinhadas. Certamente, ruas e edificações estão sujeitas a pressões funcionais distintas. A rua é canal de movimento público, a edificação abriga atividades localizadas de acessibilidade controlada. Essa distinção não referenda, todavia, o trato autônomo dos problemas de projeto respectivos. Quaisquer que sejam as especificações quantitativas e qualitativas de uma trama de ruas e quadras sobre as quais se implantem edificações, o movimento nmas ruas tem origem ou destino nas edificações, em primeira instância. Focos e canais de movimento são sempre interdependentes do ponto de vista funcional. Rigosamente falando, liberar a edificação da rua é um contra-senso lógico. Por outro lado, ruídos e gases gerados por tráfego veicular intenso não são minimizados ou eliminados automaticamente pela descontinuidade e desalinhamento das edificações; problemas de iluminação, insolação e ventilação se resolvem após consideração judiciosa da interação entre condicionantes de situação e condicionantes de funcionalidade. Uma fachada resulta de pressões internas e pressões externas, quando mais não seja porque considerações econômicas premiam a redução de sua área. Ao mesmo tempo, a experiência mostra que não há determinismo funcional na geração da forma arquitetônica; em regra, o mesmo conjunto de requerimentos pode ser satisfeito em diferentes volumes.

Se a hierarquização da trama viária urbana é recomendação sensata, o mesmo não pode ser dito da rejeição da rua tradicional. A observação da realidade de sua utilização na cidade brasileira revela uma riqueza e complexidade que a sua definição como caminho público flanqueado por edificações está longe de tornar explícita. Pontos de encontro, de comércio, de brinquedo, de celebração coletiva, de socialização, elas são também unidades percentuais de nossa leitura do espaço urbano, elementos básicos para a elaboração do mapa mental que permite nossa orientação através do mesmo. É claro que essa multifuncionalidade é positivia (Jacobs, 1961), ainda que encerre conflitos.

A resposta adequada à compatibilização de funções diversas, entretanto, não é necessariamente a segregação e especialização espaciais absolutas. Entendido e aceite o papel recreativo da rua residencial, caberia verificar, por exemplo, a validade de padrões para áreas recreativas urbanas endossados hoje sem questionamento. A rejeição da rua tradicional e a promoção irrefletida de blocos isolados, 'livremente' dispostos em relação à mesma, pela 'ci- 
dade ideal moderna' tem induzido a desprezar as relações de interdependência funcional e figurativa entre rua e edificação. O espaço da rua passa a ser resíduo. Até mesmo em mãos dotadas, a liberdade de implantação equivalente ao abandono da disciplina do alinhamento pode se converter em aleatoriedade arbitrária de implantação. Não estranha, portanto, que a orientação seja difícil no conjunto de apartamentos $\mathrm{BNH}$.

Sugerimos anteriormente que a repetitividade em larga escala de blocos idênticos desempenha também um papel nessas dificuldades de orientação. Tal repetitividade não deixa de ser um eco longínquo da prescrição modernista de redução de tipos de acomodação residencial na cidade, partindo-se da convergência entre requerimentos de industrialização e um número reduzido de necessidades mínimas do homem-tipo anônimo da sociedade de massas. A regra concebia a construção como um processo análogo à produção de automóveis ou navios. Esquecia, porém, que muitas partes dos edifícios eram já, de certa maneira, pré-fabricadas em 1930, sem dar lugar ao fenômeno da industrialização; que as grandes séries repetitivas adequavamse à produção de copos ou parafusos, nunca à de locómotivas ou aviões; que a indústria tende a reduzir ao mínimo o armazenamento de peças de reposição de consumo freqüente; e, finalmente, que os fluxos de trabalho na indústria não dependem conceitualmente do produto fabricado, mas sim de um modo específico de programação de atividades. A produção industrial de componentes construtivos de pequeno e médio porte, tirando plena vantagem das economias de escala de uma produção em massa, não requer automaticamente a cartelização das empresas responsáveis por sua montagem no canteiro. A centralização física e financeira da produção de componentes construtivos não impede a descentralização física e financeira dos agentes construtores.

Tudo isso posto, torna-se difícil defender a 'cidade ideal moderna', em termos de desempenho funcional. Embora ostensivamente ela se pretenda norma apoiada em critérios de higiene, eficiência técnica e racionalidade econômica, quando examinada mais a fundo revela-se dependente de proposições discutíveis, que não estão lógica e indissoluvelmente relacionadas. Na melhor das hipóteses, configura uma alternativa de projeto, nunca uma regra categórica. O seu apelo básico é simbólico. Ela celebra um admirável mundo novo, onde o progresso científico e tecnológico garantiria a concretização do sonho revolucionário de liberdade, igualdade e fraternidade, em total harmonia com a natureza. Em decorrência de uma homogeneização e integração culturais supostamente inevitáveis, desapareceria a necessidade de qualquer elaboração protetora entre domínio público e domínio privado, entre liberdade individual e autoridade coletiva. A lógica interna do avanço técnico-científico imporia a democratização econômica, a justiça e a paz sociais, a reconciliação entre campo e cidade, artefato humano e paisagem natural. A verdade e a ordem prevaleceriam, transparentes, porque, como na utopia clássica, no admirável mundo novo os homens não teriam outra escolha senão a bondade. Cristalina, brilhante, incorruptível, a 'cidade ideal moderna' se coloca fora do tempo e da História, fundindo, numa só imagem, o mito da perfeição futura e o mito da perfeição passada: a Nova Jerusalém secular e o Jardim do Éden ancestral (Rowe; 1978).

Não importa que, em retrospecto, a ingenuidade dessa amálgama de determinismo técnicoeconômico e idealismo naturalista apareça falaciosa. A força emocional do ícone era avassaladora. Prestava-se a múltiplas conotações. No país de Capanema e Kubitschek, tornou-se emblema desenvolvimentista e afirmação de ufanismo nacionalista, do gênero 'mais uma vez a Europa se curva ante o Brasil'. Entretanto, irônica e paradoxalmente, a cidade justificada como produto de um dinamismo tecnológico sem precedentes só mantém a sua coerência físico-funcional se concebida do zero, regida pelos ditames de um plano de massa unitário, rigoroso e imutável em suas linhas gerais. A reivindicação de liberdade anula-se no imobilismo de um controle totalitário do projeto urbano, tanto mais insidioso porque se arroga benévolo e iluminado. A visão igualitária que anima a 'cidade ideal moderna' mal disfarça, afinal de contas, o endosso de uma sociedade dominada por uma elite tecnocrática, na qual o arquiteto teria papel de destaque. Quando, por impossibilidade de um controle completo do projeto urbano, os princípios modernistas forem institucionalizados em regras matemáticas aplicadas a um tecido urbano existente para premiar a menor ocupação do solo e o afastamento das divisas do lote, a construção do espigão se tornará inevitável - e os espaços abertos residuais junto à trama viária urbana, um fenômeno banal. A cidade tenderá a transformar-se numa coleção de intervenções singulares aleatoriamente justapostas. A redução da paisagem urbana à harmonia monocórdia que não admite desvio será substituída pela cacofonia desorientadora da mais desbragada permissividade. Arbítrio e arbitrariedade comandam o espetáculo. Em sua companhia instala-se o desperdício. Promovendo a convicção de que só o novo é autêntico, a 'cidade ideal moderna' legitimou, na formação arquitetônica, uma atitude de desconsideração da herança urbana brasileira, que constitui extravagância econômica e cultural. É perdulário o desprezo do investimento considerável em capital e trabalho que essa herança representa. É empobrecedora a caracterização pejo- 
rativa dos valores culturais nela cristalizados. Ao pretender libertar-nos da memória, a 'cidade ideal moderna' esqueceu que, sem memória, não há nem comunicação, nem comunidade.

Por contraste, o urbanismo de rua, praça, quadra, fachada, alinhamento, esquina, pátio e quintal revaloriza-se. Suas virtudes salientam-se: a clara caracterização de domínios públicos e privados urbanos mediante a adoção normativa da edificação contínua alinhada ao longo da rua e da praça; a versatilidade do plano de fachadas alinhadas que, ao mesmo tempo que ordena e estabiliza a paisagem pública, admite a coexistência de ritmos diversos de evolução funcional e estilística no domínio privado; a disciplina geométrica de um sistema razoável de regras morfológicas simples. Essa possibilita e mesmo estimula o diálogo entre ordem coletiva e iniciativa particular, estabilidade e mudança, constância e imprevisibilidade, regularidade e acidente, porque reconhece a conveniência de níveis diferenciados de controle e liberdade no processo de renovação e ampliação do espaço urbano.

É óbvio que não faz sentido propugnar a reprodução historicista de tipos anacrônicos no contexto técnico-econômico e cultural de hoje, nem abandonar reivindicações legítimas de conforto ambiental. Apontar inconsistência de uma fetichização do espaço aberto não significa afirmar que o espaço aberto é dispensável. Indicar a conveniência de uma desintegração territorial urbana em unidades menores que a superquadra, não equivale a endossar o quarteirão estreito e comprido do loteamento convencional ou conjunto de casinhas $\mathrm{BNH}$. A economia urbana requer densidades elevadas. A predominância da habitação coletiva no tecido residencial urbano continua sendo a resposta mais adequada para tal requerimento. A 'cidade ideal moderna' retém interesse e valor, se entendida racionalmente como proposta que detalha, de modo dimensionalmente explícito, uma articulação potencial entre componentes físico-funcionais urbanos, a partir de premissas concretas ou inferíveis com facilidade. Conseqüentemente, está aberta a um exame crítico. Podemos concluir que suas premissas são simplificadoras ou irrealistas, que as soluções encaminhadas têm alcance diminuto. Entretanto, quando nos informamos do que é teoricamente possível realizar - via o exercício combinado de especulação racional e intuição criadora - , ela é exploração que amplia nossa liberdade de opções quanto à configuração do ambiente construído.

Não é menos verdade, porém, que suas deficiências e limitações intrínsecas impelem a rejeitála como referência normativa ou instrumento apriorístico de projeto da cidade e da moradia brasileira, afirmando a necessidade de superar a identificação tácita entre conjunto habitacional e habitação popular que hoje prevalece no país. Em tempos não muito distantes, conjunto planejado de habitações populares nomeava-se vila. O termo é simpático: usado ainda hoje para designar conjunto espontâneo de habitações populares, evoca uma urbanidade perdida pelo conjunto $\mathrm{BNH}$. Conjugado com o conceito de bairro, cujas conotações são mais ricas e complexas que as da asséptica zona monofuncional modernista, poderia alimentar outra postura no trato do problema de projeto da habitação de baixa renda, fazendo entendê-lo como problema de projeto das vilas e bairros populares brasileiros. Sejam produto de operações de expansão ou renovação urbana, empreendimentos de recuperação de áreas faveladas ou urbanização de vazios citadinos de qualquer porte, bairros e vilas populares podem e devem ser concebidos como componentes físico-runcionais positivamente integrados à cidade onde se assentam. Suas ruas, travessas, becos e caminhos devem conetarse consistentemente com a trama viária municipal. Suas praças devem ser elementos de uma rede municipal de recreação. A multifuncionalidade potencial da rua deve ser plenamente considerada e viabilizada. Os espaços habitacionais propriamente ditos devem coordenar-se física e funcionalmente com os equipamentos, serviços e locais de trabalho existentes no entorno ou cuja implantação se faz oportuna e conveniente. Domínios públicos, semipúblicos e privados precisam ser claramente caracterizados e consistentemente articulados. A adoção normativa de edificações alinhadas defrontando ruas ao longo dos limites de quadra facilita a obtenção de boas condições de identificação e apropriação territoriais, fornecendo evidência imediata de responsabilidades de manutenção e gerência espaciais. A repetividade induzida por motivos econômicos pode ser temperada pela arborização variada de ruas e praças, bem como pelo aproveitamento judicioso de todas as oportunidades legítimas de diferenciação formal que decorrem de variações situacionais ou funcionais: acessos, esquinas, coberturas, térreo e assim por diante.

Além do mais, nem a densidade elevada nem a predominância da habitação coletiva recomendáveis por questão de economia prefiguram inexoravelmente a monotonia na vila ou bairro popular. A idéia de habitação coletiva pode ser expandida para incluir também o condomínio horizontal - forma de propriedade jurídica já consagrada juridicamente no país. Pensar a habitação coletiva como condomínio residencial sugere não apenas uma limitação de escala que constrasta com o gigantismo do conjunto habitacional típico, como amplia a gama de opções tipológicas visualizáveis para as unidades habitacionais propriamente ditas. Quadras condominais à base de casas térreas e/ou assobradadas em fita po- 
dem atingir uma densidade líquida da ordem dos 300 a $400 \mathrm{hab} / \mathrm{ha}$, sem qualquer prejuízo de habitabilidade, aliando atrativos da residência unifamiliar (como acesso indivdualizado, vinculação direta com pátio privativo, possibilidade de ampliações), com a possibilidade de dispor de espaços e equipamentos economicamente inviáveis na residência unifamiliar modesta. Eliminando a obrigatoriedade de coletivização de todo espaço aberto, apartamentos térreos também poderão ser dotados de pátios privativos e até mesmo de acessos individualizados. A casa de altos e baix.os em fita poderá ser considerada novamente como alternativa: não há razão alguma que imponha como necessidade universal a posse de espaço aberto, particularmente quando não se tem automóvel - o que é regra e não exceção nas camadas de menor poder aquisitivo. Igualmente, mesmo em regime de propriedade individual, é possível obter densidades razoáveis com casas de porta-e-janela e sobrados em fita. Um quarteirão quadrado poderia comportar tanto pequenos condomínios horizontais como casas unifamiliares em fita de testa reduzida: pode-se construir sobrado em 4,5m de testada, em ótimas condições. Usando raciocínio similar em sentido inverso, urbanizações à base de casasenabrião ou lote-e-serviços resultarão mais econômicas em infra-estrutura viária, se concebidas a partir de quarteirões quadrados parcelados em superlotes, condominiais, onde se individuem espaços privativos e coletivos, ou em combinação de pequenos lotes unifamiliares e superlotes condominiais. A diversidade potencial de soluções não é ilimitada, mas não se esgota no conjunto antieconômico de casinhas isoladas e no conjunto habitacional modernista corrompido.

O exame que aqui fizemos do conjunto habitacional BNH como referência normativa do projeto da habitação popular brasileira não se pretendeu exaustivo; as alternativas sugeridas devem ser entendidas como um esboço de possibilidades a desenvolver. Suas implicações técnico-econômicas e culturais merecem ser examinadas com maior rigor e comparadas com o desempenho correspondente de conjuntos habitacionais já realizados. A dissociação recomendada entre conjunto habitacional e habitação popular, entretanto, permite que sejam percebidas relações entre o problema de projeto da habitação popular e outros tipos que fazem parte de um rico acervo de configurações arquitetônicas conhecidas e já testadas em outros momentos no país. Permite pensar na recuperação de uma memória arquitetônica e urbanística desprezada levianamente em benefício de um futurismo empobrecedor. Seria ingênuo, porém, subestimar os formidáveis mecanismos institucionais e ideológicos que sustentam a realização do conjunto habitacional $\mathrm{BNH}$ e contribuem para inviabilizar estratégias inovadoras no pro- jeto da habitação popular. Entre eles está a legislação arquitetônica e urbanística vigente, que perpetua preconceitos tipológicos associados ao sonho da 'cidade ideal moderna', como a exigência de baixas taxas de ocupação, recuos frontais e laterais, e assim por diante. De uma maneira geral, ela não distingue entre os elementos e relações físicas urbanas cuja conservação, materialização ou alteração interessam obrigatoriamente à comunidade e aqueles que podem licitamente ser deixados à iniciativa particular. Sua tendência é dar excessiva liberdade ao projeto do espaço público e excessiva rigidez ao projeto dos domínios privados. Além disso, a legislação peca demasiado freqüentemente por irrealismo, aplicando-se sem discernimento, num contexto notoriamente carente, critérios, normas e especificações mais exigentes dos paises mais ricos. A desproporção se torna mais sensível à medida que se baixa na escala econômica da população. Normas, critérios e especificações irrealistas reduzem o número de soluções oferecidas legalmente e formentam invasões e loteamentos clandestinos de baixa qualidade urbanística. Seguramente o problema da escassez das soluções habitacionais não se eliminaria somente com a diminuição de custos gerada por normas mais austeras baseadas no conceito de uma qualificação progressiva por etapas de vilas e bairros populares. Todavia, é possível presumir que se lograriam avanços substanciais (Trujillo, Gnecco et alii), quando a realidade do subdesenvolvimento fosse reconhecida e aceita como o ponto de partida para o uso eficiente e imaginativo de recursos limitados.

\section{Notas}

1. $601 \mathrm{hab} / \mathrm{ha}$ é a ordem de grandeza média dos 40 conjuntos ilustrados em BNH: projetos sociais, publicado pelo próprio banco em 1979.

2. A cidade ideal moderna pode ser chamada também de 'cidade da Carta de Atenas' - relatório-manifesto urbanístico, produto final do $4^{\circ}$ Congresso Internacional de Arquitetura Moderna realizado em Atenas no verão de 1933.

3. O ensaio de Gropius está descrito no livro citado de Martin e Match.

\section{Bibliografia}

Banco Nacional de Habitação - BNH: projetos sociais. Rio, The death and life of great american cities, 1979.

JACOBS, Jane. American cities, Nova York, Vintage Books, 1961. LE CORBUSIER, pseud. de Charles Edouard Jeanneret-Gris. La Charte d'Athénes. Paris, Plon, 1943.

MARTIN, March, ed. Urban spaces and structures. Londres, Cambridge University Press, 1972

ROWE, Colin \& KOETTER, Fred. Collage city. The MIT Press. Cambridge, Mass, 1978.

SOMMER, Robert. Personal space. New Jersey, Prentice-Hall Inc, s.d.

TRUJILLO, Anibal Lopez e outros. Estudio de normas mínimas de urbanización, servicios públicos y servicios comunitarios. In Escala, 65. Colombia. 